\title{
Carbonylation of glycerol with urea to glycerol carbonate over supported Zn catalysts
}

\author{
S. E. Kondawar ${ }^{1}$ - R. B. Mane $^{1} \cdot$ A. $\operatorname{Vasishta}^{1} \cdot$ S. B. More ${ }^{1}$ - S. D. Dhengale ${ }^{1}$. \\ C. V. Rode ${ }^{1}$
}

Received: 22 November 2016/Accepted: 29 March 2017/Published online: 20 April 2017

(c) The Author(s) 2017. This article is an open access publication

\begin{abstract}
Glycerol carbonylation with urea is a very feasible option to produce glycerol carbonate with a net result of $\mathrm{CO}_{2}$ fixation through urea synthesis. The prerequisite of an efficient catalyst for this reaction is to possess both acid and basic sites together. Several acidic supports were screened for $\mathrm{ZnO}$ catalyst in this work and $\mathrm{Zn} / \mathrm{MCM}-41$ was found to exhibit the best activity and almost complete selectivity to glycerol carbonate (GC). Although, non-catalytic glycerol carbonylation resulted in GC formation but glycerol conversion achieved was twice with Zn/MCM-41 as a catalyst. Further to that increase in $\mathrm{Zn}$ loading from 2 to $5 \%$ resulted in increase in glycerol conversion from 63 to $82 \%$. The prepared catalysts were characterized by $\mathrm{XRD}, \mathrm{NH}_{3}$ and $\mathrm{CO}_{2}$-TPD and effects of reaction parameters such as catalyst loading, glycerol to urea mole ratio and temperature on glycerol conversion and GC selectivity in batch mode of operation were also studied. Time on stream activity of 5\% Zn/MCM-41 catalyst for continuous carbonylation of glycerol was also studied for $\sim 100 \mathrm{~h}$ with an average conversion of $\sim 55 \%$ and complete selectivity to GC. This indicated five times lower productivity of GC per $\mathrm{h}$ due to lower residence time than that in a batch operation as compared to that of a continuous operation. Activation energy estimated from the Arrhenius plot was found to be $39.82 \mathrm{~kJ} \mathrm{~mol}^{-1}$ suggesting that the reaction is kinetically controlled. A reaction pathway mediated by acid and basic sites of the $\mathrm{Zn} / \mathrm{MCM}-41$ catalyst is also proposed.
\end{abstract}

C. V. Rode

cv.rode@ncl.res.in

1 Chemical Engineering and Process Development Division, CSIR-National Chemical Laboratory, Dr. Homi Bhabha Road, Pune, Maharashtra 411008, India
Keywords Supported $\mathrm{Zn}$ - Glycerol-urea carbonylation · Glycerol carbonate $\cdot$ Zn loading $\cdot$ Acid-base ratio . Reaction pathway $\cdot$ Continuous process

\section{Introduction}

Biodiesel produced by transesterification of triglycerides has created a practical option at least partially, for fossil fuel [1]. In recent years, increased biodiesel production has also led to a large scale availability of glycerol which necessitates its valorization by exploring new avenues [2]. Arising from the need of utilization of bioglycerol, one of the attempts involves the synthesis of glycerol carbonate which is a high value monomer for polycarbonate synthesis as well as a polar solvent having an excellent biodegradability, low toxicity and miscibility with water [3-5]. Glycerol carbonate (GC) is also used as an intermediate in the synthesis of pharmaceuticals, fine chemicals and agricultural chemicals [3-5].

GC synthesis has been reported primarily by catalytic carbonylation of glycerol with $\mathrm{CO} / \mathrm{O}_{2}$ or phosgene. The oxycarbonylation of diols also has been reported using $\mathrm{Pd} /$ $\mathrm{Mn}$ redox catalyst system [6]. Nevertheless, use of CO or phosgene in such processes poses serious environmental and handling drawbacks due to their hazardous nature [7-10]. Direct carbonylation using $\mathrm{CO}_{2}$ although a preferred route for making $\mathrm{GC}$, it is thermodynamically unfavorable offering very low yield $(<25 \%)$ of GC $[11,12]$. Attempts made for $\mathrm{CO}_{2}$ activation involved very high pressure $(>5 \mathrm{MPa})$ and temperature $\left(>180{ }^{\circ} \mathrm{C}\right)$ conditions with $<50 \%$ glycerol conversion and trace formation of $\mathrm{GC}$ [13]. In another variation, cycloaddition of $\mathrm{CO}_{2}$ with glycidol resulted into higher GC yield of $>92 \%$. However

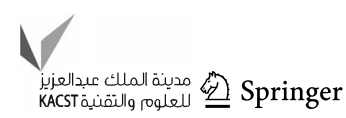


the starting material glycidol obtained from GC is costlier than GC, making this process uneconomical for industrial exploitation [11]. Glycerol transesterification with alkyl carbonates can be one of the viable options for GC in which complete glycerol conversion with $>75 \% \mathrm{GC}$ selectivity has been reported [12]. However, making of alkyl carbonates in turn proceeds through phosgene or energy intensive epoxide routes. GC can also be produced by direct carbonation of glycerol with ethylene carbonate under supercritical $\mathrm{CO}_{2}$ using zeolite as a catalyst [14]. However, there is no evidence that a direct $\mathrm{CO}_{2}$ insertion occurred and glycerol carbonate was only produced when another organic carbonate was added as a reactant. The most widely studied route of GC synthesis is the transesterification of glycerol with dimethyl carbonate (DMC) $[15,16]$, ethylene carbonate (EC) $[17,18]$ and propylene carbonate (PC) [19]. However, these cyclic carbonates used for transesterification are typically synthesized either from phosgene utilization or energy intensive route involving epoxide. Use of EC leads to formation of ethylene glycol that involves tedious work-up procedure. Although DMC was exploited for transesterification with glycerol using basic catalysts like $\mathrm{K}_{2} \mathrm{CO}_{3}, \mathrm{CaO}$ and $\mathrm{Ca} / \mathrm{La}$ mixed oxide but the recyclability of these catalysts was not established $[20,21]$. Compared to the above-mentioned routes for GC, carbonylation of glycerol with urea proves to be greener, cheaper and atom economic for the synthesis of GC. Urea produced by reaction of $\mathrm{CO}_{2}$ and ammonia with a worldwide capacity of $10^{8}$ tpa is the well established example of chemical utilization of $\mathrm{CO}_{2}$. It follows that glycerol carbonylation via urea route establishes the indirect utilization of $\mathrm{CO}_{2}$. Moreover, $\mathrm{NH}_{3}$ evolved in this carbonylation process becomes available again for urea production (Scheme 1). Among the several catalytic systems reported for this reaction, homogeneous catalysts include the salts of $\mathrm{Mn}, \mathrm{Zn}$ and $\mathrm{Zr}$ [13, 22-25], while heterogeneous systems include $\mathrm{Zn}$-hydrotalcite [25], $\mathrm{Co}_{3} \mathrm{O}_{4} / \mathrm{ZnO}$ [26], solid base like $\mathrm{La}_{2} \mathrm{O}_{3}$ etc. [27]. It is exceptional that Hammond et al. reported noble metal like $\mathrm{Au}$ supported on $\mathrm{MgO}$ but with glycerol conversion of $88 \%$ and a much lower selectivity of $56 \%$ to GC [28]. Recently, Cs-exchanged heteropolyacid functionalized with $\mathrm{Sn}$ catalysts were reported giving glycerol conversion of $91 \%$ however, GC selectivity was

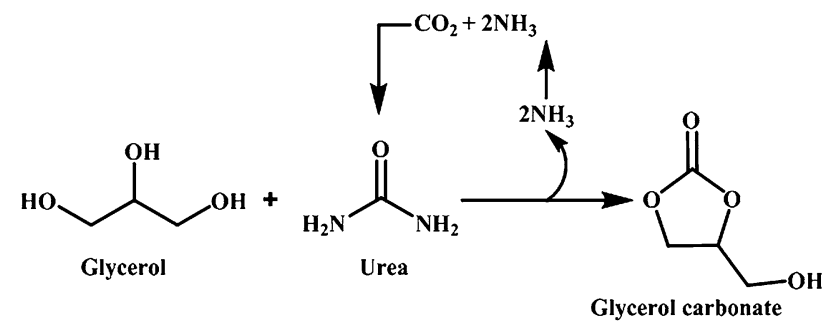

Scheme 1 Glycerol carbonate synthesis using urea as $\mathrm{CO}_{2}$ donor hampered $(83 \%)$ due to the formation of undesired byproducts such as GD and glycerol urethane [29]. These systems reported so far have some other common drawbacks of higher catalyst to substrate ratio, use of high vacuum for $\mathrm{NH}_{3}$ removal thus making the process cost intensive in terms of higher energy and catalyst consumption.

Recently, we have reported screening study of various MCM-41 supported $\mathrm{Cu}, \mathrm{Ni}$ and $\mathrm{Zn}$ oxide catalysts for glycerol carbonylation with urea to give GC [30]. In continuation, we studied in detail the role of different supports and loading of $\mathrm{Zn}$ in glycerol-urea reaction to produce GC. Effect of reaction parameters such as temperature, catalyst loading and glycerol to urea ratio was also performed to arrive at optimized reaction conditions. In addition, the performance comparison in batch and continuous operations showed that much higher conversion was obtained in a batch process due to higher residence time in the later.

\section{Experimental details}

\section{Catalysts preparation}

The support MCM-41 was first prepared by hydrothermal method reported in the literature [30]. In a typical preparation, $2.67 \mathrm{~g}$ of sodium hydroxide was dissolved in $146 \mathrm{~g}$ of distilled water and stirred for $5 \mathrm{~min}$. To that solution, $5.96 \mathrm{~g}$ of cetyltrimethylammonium bromide (CTAB, Aldrich Chemicals, Bangalore, India) was added and the mixture was stirred for $15 \mathrm{~min}$. To this, $14 \mathrm{~g}$ of tetraethyl orthosilicate (TEOS) was added drop wise and $\mathrm{pH}$ of the gel was maintained at 9-10 using dilute $\mathrm{H}_{2} \mathrm{SO}_{4}$ solution. The resultant gel was stirred for further $5 \mathrm{~h}$ at room temperature. It was then transferred into a Teflonlined stainless steel autoclave and heated to $373 \mathrm{~K}$ for $48 \mathrm{~h}$. The solid product was filtered, washed with distilled water, dried at $353 \mathrm{~K}$ and finally calcined at $813 \mathrm{~K}$ for $6 \mathrm{~h}$.

$5 \% \mathrm{Zn}$ catalysts on different supports like MCM-41, SBA-15, $\mathrm{ZrO}_{2}, \mathrm{SiO}_{2}, \mathrm{Al}_{2} \mathrm{O}_{3}$ and sulphated $\mathrm{ZrO}_{2}\left(\mathrm{~s}-\mathrm{ZrO}_{2}\right)$ were synthesized by wet impregnation method. In a typical procedure, $0.33 \mathrm{~g}$ of zinc acetate dihydrate $\left(\mathrm{Zn} \quad\left(\mathrm{O}_{2}\right.\right.$ $\left.\mathrm{CCH}_{3}\right)_{2}\left(\mathrm{H}_{2} \mathrm{O}\right)_{2}$ ) was dissolved in $10 \mathrm{~mL}$ of water and was stirred for $5 \mathrm{~min}$, followed by the slow addition of the respective support to the solution. The solution was kept under stirring for $6 \mathrm{~h}$ at room temperature in nitrogen atmosphere. Then the solvent was evaporated on a rotavap and the catalysts were calcined at $813 \mathrm{~K}$ for $3 \mathrm{~h}$. The prepared catalysts were nominated as $\mathrm{Zn} / \mathrm{MCM}-41, \mathrm{Zn}$ / SBA-15, $\mathrm{Zn} / \mathrm{ZrO}_{2}, \mathrm{Zn} / \mathrm{SiO}_{2}, \mathrm{Zn} / \mathrm{Al}_{2} \mathrm{O}_{3}$ and $\mathrm{Zn} /$ sulfated $\mathrm{ZrO}_{2}$, respectively. 


\section{Characterization}

The crystallinity and phase purity of all the prepared catalysts were analyzed by X-ray diffraction (XRD) patterns on a P Analytical PXRD system (Model X-Pert PRO1712), using Ni filtered $\mathrm{Cu} K \alpha$ radiation $(\lambda=0.154 \mathrm{~nm})$ as an X-ray source (current intensity, $30 \mathrm{~mA}$; voltage, $40 \mathrm{kV}$ ) and an $\mathrm{X}$-accelerator detector. The samples were scanned in a $2 \theta$ range of $0^{\circ}-10^{\circ}$ and $10^{\circ}-90^{\circ}$. The species present in the catalysts were identified by their characteristic $2 \theta$ values of the relevant crystalline phases. The software program X-Pert High Score Plus was employed to subtract the contribution of the $\mathrm{Cu} \mathrm{K} \alpha 2$ line prior to data analysis. BET surface areas and $\mathrm{NH}_{3}, \mathrm{CO}_{2}$-TPD measurements were carried out by the adsorption/desorption of nitrogen $(77 \mathrm{~K})$, $\mathrm{NH}_{3}, \mathrm{CO}_{2}$, respectively, using Micromeritics Chemisorb 2720 instrument. To evaluate acidity and basicity of the catalysts, ammonia and carbon dioxide TPD measurements were carried out by: (1) pre-treating the samples from room temperature to $200{ }^{\circ} \mathrm{C}$ under helium flow rate of $25 \mathrm{~mL} \mathrm{~min}{ }^{-1}$, (2) adsorption of ammonia/carbon dioxide at $40{ }^{\circ} \mathrm{C}$ and (3) desorption of ammonia/carbon dioxide with a heating rate of $10^{\circ} \mathrm{C} \mathrm{min}^{-1}$ starting from the adsorption temperature to $700{ }^{\circ} \mathrm{C}$. The particle size, morphology, and elemental composition were studied using transmission electron microscope (HR-TEM), model JEOL 1200 EX. For this purpose, the sample was prepared by sonicating a small amount of the solid sample in ethanol for half an hour. A drop of the prepared suspension was deposited on a $\mathrm{Cu}$ grid coated with carbon layer and the grid was dried at room temperature before the analysis.

\section{Activity testing}

\section{Batch operation}

The catalytic reaction of glycerol and urea was carried out in a $50 \mathrm{~mL}$ three neck round bottom flask, equipped with a condenser. In a typical reaction, respective catalyst $(0.23 \mathrm{~g})$, glycerol $(50 \mathrm{mmol})$, and urea $(50 \mathrm{mmol})$ were charged into the reactor. The reaction mixture was heated in a silicon oil bath at $140{ }^{\circ} \mathrm{C}$ in the absence of any solvent under nitrogen flow of about $10 \mathrm{~mL} \mathrm{~h}^{-1}$. After completion of the reaction, $10 \mathrm{~mL}$ of methanol $(\mathrm{MeOH})$ was added in the reaction crude followed by filtration to remove the catalyst. Repeated washings with $\mathrm{MeOH}$ were given to the solid catalyst. Liquid samples were withdrawn from the reactor and analyzed by gas chromatography to monitor the progress of the reaction. For this purpose, the gas chromatograph, Shimatzu 2025 equipped with HP-FFAP column $(30 \mathrm{~m}$ length $\times 0.53 \mathrm{~mm}$ ID $\times 1 \mu \mathrm{m}$ film thickness) and a flame ionization detector was used.

\section{Continuous operation}

Continuous carbonylation of glycerol was carried out in a bench-scale, fixed bed reactor supplied by M/s Geomechanique, France. The powdered catalyst was pelletized in the form of pellets of $1.3 \mathrm{~cm}$ diameter and cut into four pieces each having $0.65 \mathrm{~cm}$ diameter (Fig. 1). $3 \mathrm{~g}$ of the pelletized catalyst was charged to the reactor. Reaction conditions used for the continuous operation are given in Table 1. The section of $17.4 \mathrm{~cm}$ above and $13 \mathrm{~cm}$ below the catalyst bed was packed with carborundum as an inert packing, thus providing the length of catalyst bed of $8.1 \mathrm{~cm}$. Before starting the actual experiment, a flow of $\mathrm{N}_{2}$ $\left(20 \mathrm{~mL} \mathrm{~h}^{-1}\right)$ was maintained through the reactor. The liquid feed was "switched on" after attaining the desired temperature. The reactor feed flow was maintained for $1 \mathrm{~h}$ to obtain the constant liquid flow rate. Liquid samples were withdrawn at regular intervals of time. Liquid samples were analyzed by Shimatzu 2025 GC equipped with HPFFAP column $(30 \mathrm{~m}$ length $\times 0.53 \mathrm{~mm}$ ID $\times 1 \mu \mathrm{m}$ film thickness) and a flame ionization detector. Following this procedure, the experiments were carried out at different inlet conditions. Steady-state performance of the reactor was observed by analysis of the reactant and products in the exit stream.

\section{Results and discussion}

\section{Catalyst characterization}

Glycerol carbonylation with urea requires both acid and base sites; hence, the primary aim of this work was to understand the role of support and $\mathrm{Zn}$ loading in this reaction. For this purpose, a systematic characterization of the catalysts was carried out as discussed below. Table 2 shows the surface areas of different supports for a constant loading of $\mathrm{Zn}(5 \%)$. As seen from Table 2, $\mathrm{Zn}$ supported on MCM-41 catalyst showed the maximum surface area of $692 \mathrm{~m}^{2} \mathrm{~g}^{-1}$ which varied with the supports in the descending order of MCM-41 $>\mathrm{SBA}-15>\mathrm{SiO}_{2}>-$ $\gamma-\mathrm{Al}_{2} \mathrm{O}_{3}>\mathrm{ZrO}_{2}>\mathrm{s}-\mathrm{ZrO}_{2}$ in accordance with the nature of

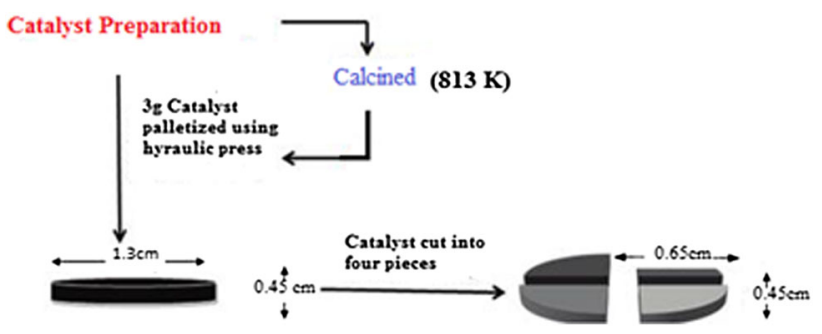

Fig. 1 Schematic representation of Zn/MCM-41 catalyst pelletization 
Table 1 Range of operating conditions

\begin{tabular}{ll}
\hline Parameter & Range \\
\hline Initial concentration of glycerol $(\mathrm{wt} \%)$ & 26 \\
Solvent & Water \\
Temperature $\left({ }^{\circ} \mathrm{C}\right)$ & $140-200$ \\
$\mathrm{~N}_{2}$-flow $\left(\mathrm{mL} \mathrm{h}^{-1}\right)$ & 20 \\
Liquid velocity $\left(\mathrm{LHSV}, \mathrm{h}^{-1}\right)$ & $0.1-0.34-0.5$ \\
Catalyst packing length $(\mathrm{cm})$ & 8.1 \\
Density of catalyst $\left(\mathrm{g} \mathrm{m}^{-3}\right)$ & 0.66 \\
\hline
\end{tabular}

Table 2 BET surface areas of supported 5\% $\mathrm{Zn}$ catalysts

\begin{tabular}{lc}
\hline Catalyst & BET surface area $\left(\mathrm{m}^{2} \mathrm{~g}^{-1}\right)$ \\
\hline $\mathrm{Zn} / \mathrm{MCM}-41$ & 692 \\
$\mathrm{Zn} / \mathrm{SBA}-15$ & 512 \\
$\mathrm{Zn} / \mathrm{SiO}_{2}$ & 466 \\
$\mathrm{Zn} / \gamma-\mathrm{Al}_{2} \mathrm{O}_{3}$ & 108 \\
$\mathrm{Zn} / \mathrm{ZrO}$ & 20 \\
$\mathrm{Zn} /$ sulphated $\mathrm{ZrO}_{2}$ & 8 \\
\hline
\end{tabular}

the support material (discussed later). MCM-41 having the maximum surface area was used for further study on $\mathrm{Zn}$ loading variation in the range of 2-10\%. Figure 2 shows $\mathrm{Zn}$ loading vs. surface area along with GC yield profiles. As expected, surface area decreased from 692 to $498 \mathrm{~m}^{2}$ $\mathrm{g}^{-1}$ with increase in $\mathrm{Zn}$ loading from 2 to $10 \%$. Although the trend is not linear, it indicates the dispersion of $\mathrm{Zn}$ within the mesoporous structure of silicalite MCM-41 and simultaneously affecting the uniform ordering of the mesoporous structure as can be seen from the XRD analysis. The increased dispersion of $\mathrm{Zn}$ with increase in loading has directly reflected in the enhancement of GC yield from 57 to $83 \%$. This suggests that the catalytic activity cannot be simply correlated to the surface area of the catalysts. Further interpretation of the activity results was deduced from various surface acid-base properties and structural ordering of the support material.

Figure 3A displays small-angle XRD patterns of MCM41 and SBA-15 supported Zn catalysts which showed good ordering of 2D-hexagonal structure indexed to (100), (110) and (200) reflections [31, 32]. This suggests the retention of hexagonal mesoporous ordering of the MCM-41 and SBA-15 even after $\mathrm{Zn}$ loading. Wide angle XRD patterns (Fig. 3B) of $5 \% \mathrm{Zn}$ on MCM-41, SBA-15 and $\mathrm{SiO}_{2}$ show the amorphous nature of the samples while a single broad peak at $2 \theta=23.1^{\circ}$ (411) could be attributed to orthorhombic silica. There was no any reflection corresponding to $\mathrm{ZnO}$ phase, suggesting the well dispersed nature of $\mathrm{ZnO}$ particles on the support and/or inside the framework of mesoporous supports like MCM-41 and

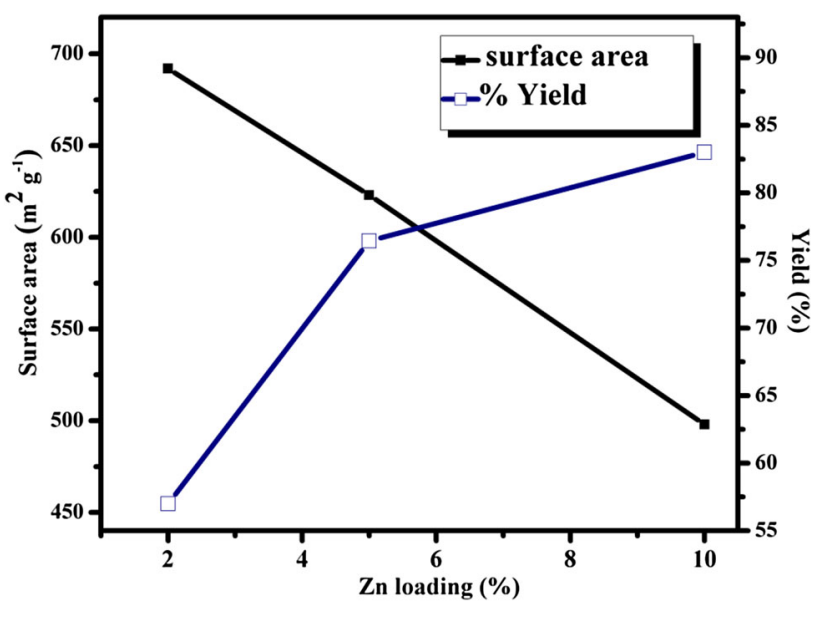

Fig. 2 Effect of $\mathrm{Zn}$ loading on surface area and GC yield

SBA-15 which is in accordance with the previous reports $[33,34]$. In case of alumina support (Fig. 3B), peaks observed at $2 \theta=37.2^{\circ}(110), 42.0^{\circ}(006), 45.3^{\circ}(202)$ and $67.1^{\circ}$ (214) were due to $\mathrm{Al}_{2} \mathrm{O}_{3}$ (JCPDF No. 81-1667) with a small peak at $2 \theta=31.7^{\circ}(100)$ of $\mathrm{ZnO}$ phase. The crystalline nature of $5 \% \mathrm{Zn} / \mathrm{ZrO}_{2}$ and $\mathrm{s}-\mathrm{ZrO}_{2}$ samples was evident by the sharp peaks (Fig. 3B) at $2 \theta=24.4^{\circ}(110)$, $28.2^{\circ}(\overline{1} 11), 41.1^{\circ}(102), 49.3^{\circ}(022), 50.6^{\circ}(\overline{1} 22)$ and $59.9^{\circ}$ (131) which were attributed to $\mathrm{ZrO}_{2}$ (JCPDF No. 83-0944). The sharp peaks observed at $2 \theta=31.7^{\circ}(100), 34.4^{\circ}(002)$, $36.2^{\circ}(101)$ and $66.4^{\circ}$ (200) could be assigned to $\mathrm{ZnO}$ phase (JCPDF No. 80-0075). This confirmed that the formation of crystalline and/or large size $\mathrm{ZnO}$ particles was possible on $\mathrm{ZrO}_{2}$ and $\mathrm{s}-\mathrm{ZrO}_{2}$ supports compared to MCM41, SBA-15, $\mathrm{SiO}_{2}$ and $\mathrm{Al}_{2} \mathrm{O}_{3}$ supports. Nature of the support obviously influenced the surface areas of the respective catalysts, as discussed above.

As 5\% Zn/MCM-41 showed the highest activity, effect of $\mathrm{Zn}$ loading on MCM-41 on structure and activity was also investigated. The low and wide angle XRD patterns of the parent MCM-41 and samples with $\mathrm{Zn}$ loading varying in the range of $2-10 \%$ are shown in Fig. 4A, B, respectively. Typical small-angle XRD of MCM-41 showed the reflections of (100), (110) and (200) planes corresponding to the ordered hexagonal mesoporous structure. In all the Zn-loaded samples, the presence of main (100) peak confirmed the unchanged hexagonal frame structure. However, loading of $\mathrm{Zn}$ varied from 2 to $10 \%$, caused shifting of the main peak (100) to higher $2 \theta$ values with a peak broadening. The other two peaks (110) and (200) with low intensity confirmed the presence of $\mathrm{ZnO}$ within the pores of MCM-41 [35]. In case of highest $\mathrm{Zn}$ loading of $10 \%$, the reflection of (100) plane weakened considerably while reflections of peaks due to (110) and (200) planes almost completely vanished. Thus, higher $\mathrm{Zn}$ loading dramatically influenced the structural ordering of MCM-41 [36]. The 
Fig. 3 A Small-angle XRD patterns of $a 5 \% \mathrm{Zn} / \mathrm{MCM}-41$, $b 5 \% \mathrm{Zn} / \mathrm{SBA}-15$, B wide-angle XRD patterns of $a 5 \% \mathrm{Zn} /$ MCM-41, $b 5 \%$ Zn/SBA- 15 , c $5 \% \mathrm{Zn} / \mathrm{SiO}_{2}$, d $5 \% \mathrm{Zn} / \mathrm{Al}_{2} \mathrm{O}_{3}$, e $5 \% \mathrm{Zn} / \mathrm{ZrO}_{2}$, f $5 \% \mathrm{Zn} / \mathrm{s}-\mathrm{ZrO}_{2}$ and $g$ Bare $\mathrm{ZnO}$

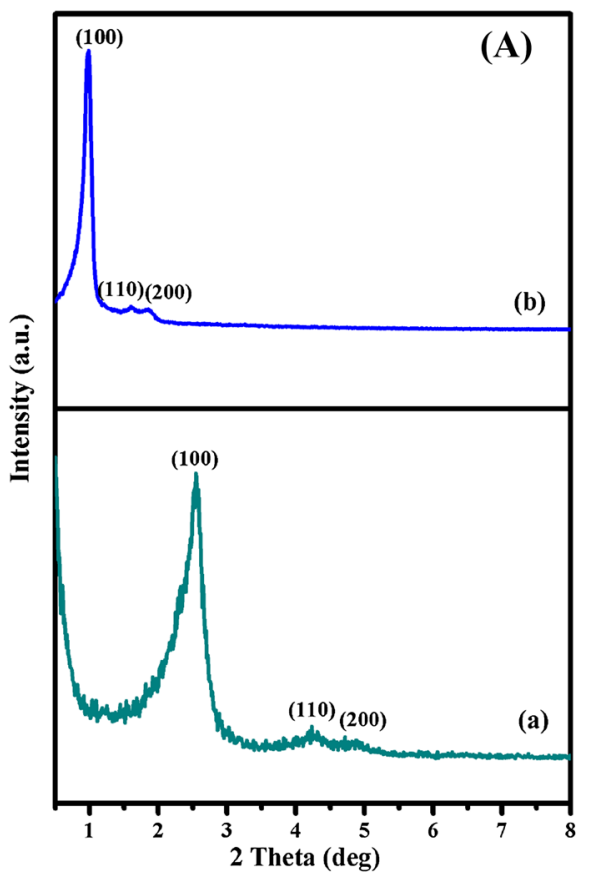

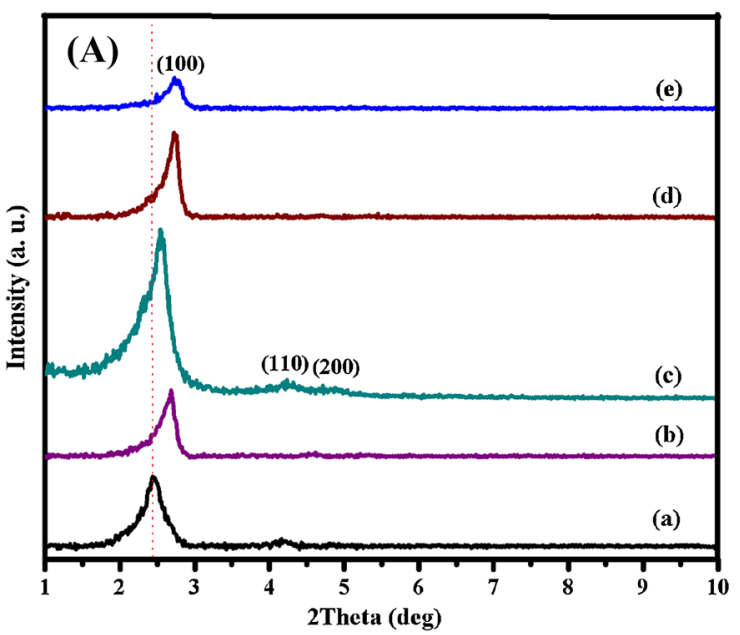

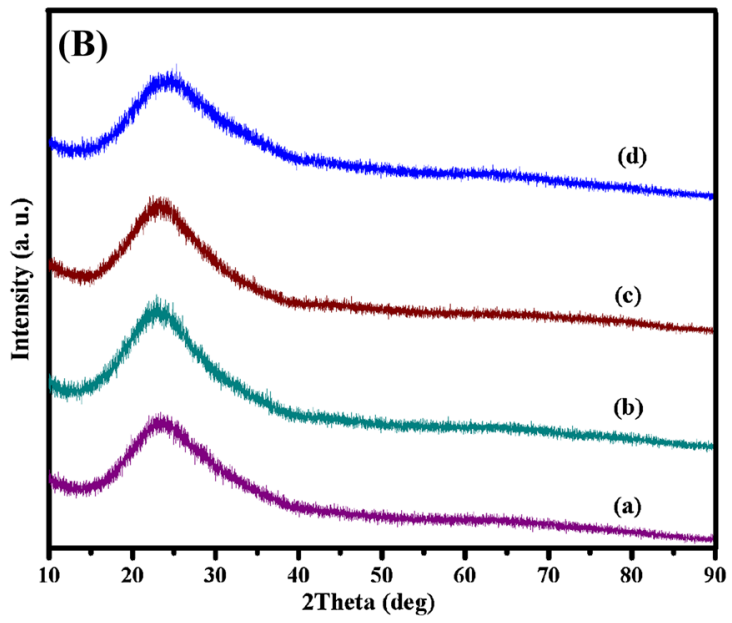

Fig. 4 A Small-angle and B wide-angle XRD patterns of Zn/MCM-41. $a$ MCM-41, $b$ 2\% Zn/MCM-41, $c$ 5\% Zn/MCM-41 and $d 10 \%$ Zn/MCM-41

wide angle XRD patterns for various Zn loadings (Fig. 4B) did not show any peak corresponding to $\mathrm{ZnO}$ confirming excellent dispersion of $\mathrm{ZnO}$ inside the pores of MCM-41. The presence of $\mathrm{Zn}(\mathrm{ZnO})$ inside the framework of the MCM-41 was also confirmed by TEM analysis coupled with EDX (Fig. 5A, B).

Activation of glycerol and urea requires both acid and base sites, respectively, to form glycerol carbonate. Hence, the catalysts prepared in this work were characterized for their acid and base strength by $\mathrm{NH}_{3}$ and $\mathrm{CO}_{2}$-TPD, respectively. In $\mathrm{NH}_{3}$-TPD plots of $\mathrm{Zn}$ catalysts with different supports (Fig. 6), the peaks below $200{ }^{\circ} \mathrm{C}$ correspond to physisorbed $\mathrm{NH}_{3}$ whereas the peaks in the temperature range of $200-400{ }^{\circ} \mathrm{C}$ represent moderate acidity while, the peaks in the range of $400-700{ }^{\circ} \mathrm{C}$ represent the strong acidity. Only in case of $\mathrm{ZrO}_{2}$ and s- $\mathrm{ZrO}_{2}$ supported $\mathrm{Zn}$ catalysts, a sharp peak observed in the range of $650-700{ }^{\circ} \mathrm{C}$ clearly suggests strong acidic strength of both the catalysts [35]. Among all the prepared catalysts, $\mathrm{SiO}_{2}$ supported catalyst showed a broad peak below $200{ }^{\circ} \mathrm{C}$ with the lowest strength of total acidity of $0.1547 \mathrm{mmol} \mathrm{g}^{-1}$ in terms of $\mathrm{NH}_{3}$ desorbed. In case of $\mathrm{Al}_{2} \mathrm{O}_{3}$ supported catalyst, a broad distribution of acidity all over the temperature range of $100-700{ }^{\circ} \mathrm{C}$ was observed 
which clearly suggests the presence of weak, moderate as well as strong acidic sites [37]. MCM-41 supported Zn catalyst showed only a single broad peak below $200{ }^{\circ} \mathrm{C}$ indicating the presence of weak acid sites.

Table 3 shows comparative data of total acidity, basicity and acid/base ratio of the various loadings of $\mathrm{Zn}$ on MCM41. Acidity of the catalysts initially increased with increasing $\mathrm{Zn}$ content up to $5 \%$ beyond which it remained almost constant at about $0.52 \mathrm{mmol}$ of $\mathrm{NH}_{3} \mathrm{~g}^{-1}$. The increased acidity after $\mathrm{Zn}$ incorporation into the silica framework was due to the formation of $\mathrm{Zn}^{2+}$ Lewis acid sites in the silica framework as well as the BrØnsted acidity due to surface silanol groups. Similar observation was also described by Silvestre-Albero et al. for $\mathrm{Zn}$ supported MCM-41 catalyst [38]. Similar to the acidity trend, basicity generated due to the oxygen anion of the $\mathrm{ZnO}$ was less in case of $2 \% \mathrm{Zn}$ loading which then increased for $5 \%$ loading and afterwards, it remained constant. The acidity/basicity ratio was found to be constant $(\sim 0.8)$ for the range of $5-10 \% \mathrm{Zn}$ loading on MCM-41. It was observed that glycerol conversion increased substantially with increase in $\mathrm{Zn}$ loading irrespective of the acid/base ratio.

\section{Carbonylation of glycerol with urea in a batch operation}

Various supports were screened for constant loading of 5\% $\mathrm{Zn}$ for the carbonylation of glycerol with urea and the results are shown in Table 4. Zn/MCM-41 showed highest conversion of $78 \%$ with maximum GC selectivity of $98 \%$ while, $\mathrm{Zn} / \mathrm{SiO}_{2}$ showed the lowest conversion of $20 \%$ but $97 \%$ selectivity to GC. In case of $\mathrm{Al}_{2} \mathrm{O}_{3}, \mathrm{ZrO}_{2}$ and s- $\mathrm{ZrO}_{2}$ supported $\mathrm{Zn}$ catalysts, glycerol conversion was about $60 \%$ but the GC selectivity decreased substantially to $67 \%$. Since, both $\mathrm{Al}_{2} \mathrm{O}_{3}$ and $\mathrm{ZrO}_{2}$ were having strong acidic sites (Fig. 6), formation of other side products such as urethanes

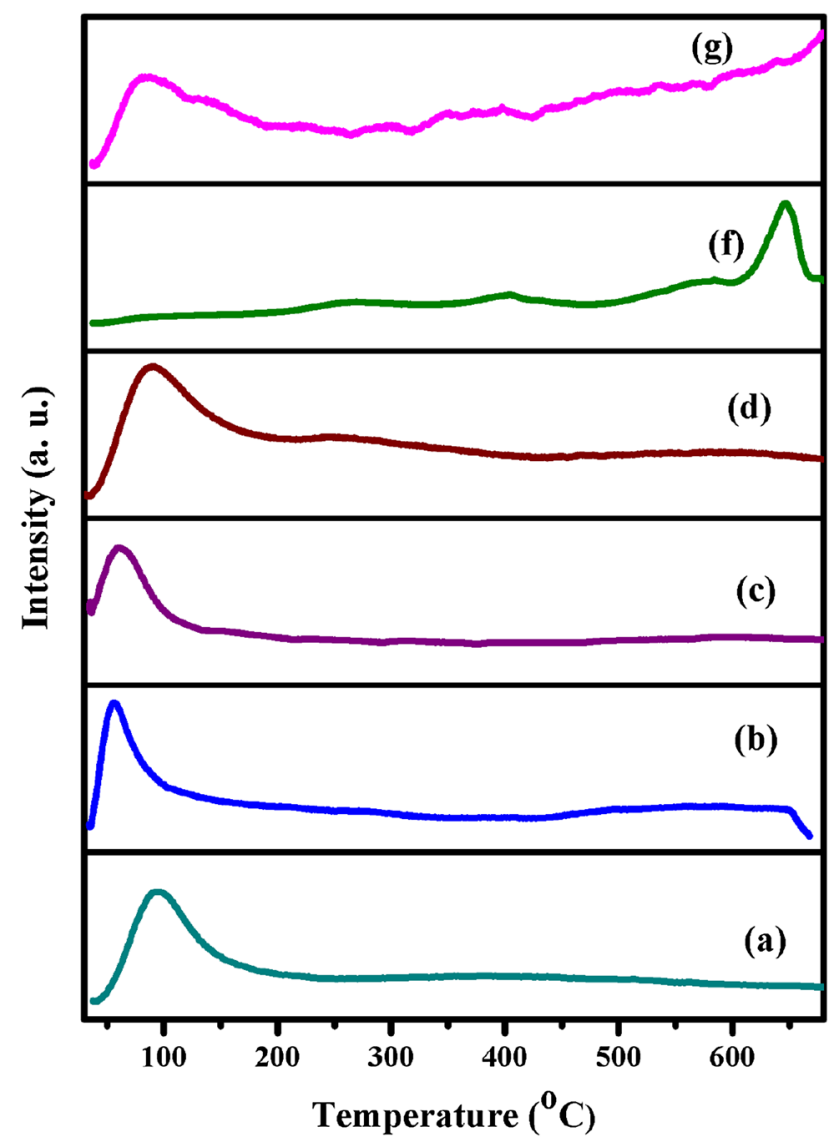

Fig. $6 \mathrm{NH}_{3}$ TPD profiles of $a$ 5\% Zn/MCM-41, $b$ 5\%Zn/SBA-15, c $5 \% \mathrm{Zn} / \mathrm{SiO}_{2}$, d $5 \% \mathrm{Zn} / \mathrm{Al}_{2} \mathrm{O}_{3}$, e $5 \% \mathrm{Zn} / \mathrm{ZrO}_{2}$ and $f 5 \% \mathrm{Zn} / \mathrm{s}-\mathrm{ZrO}_{2}$

was possible, reducing the GC selectivity [39]. It was clear from these results that the support such as MCM-41 having highest surface area was responsible for the maximum dispersion of active $\mathrm{ZnO}$ phase although having weak acidity, led to the highest activity. However, the selectivity to GC was strongly dependant on the appropriate acidity of
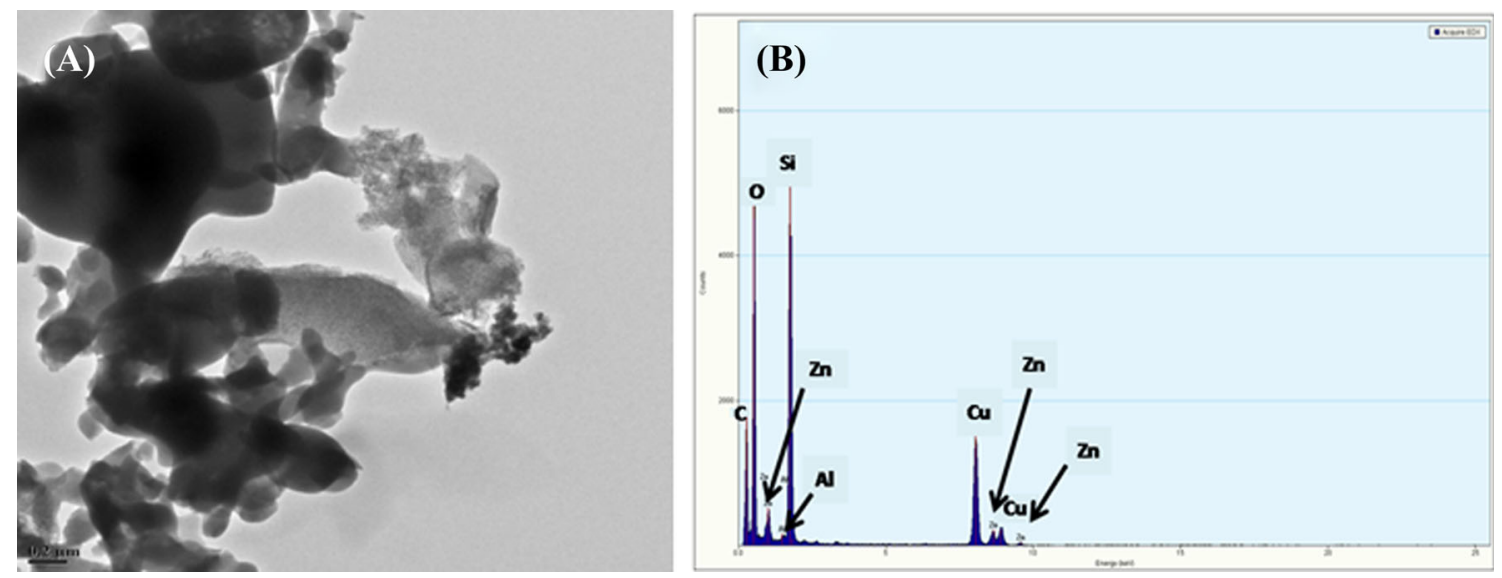

Fig. 5 HR-TEM image of A 10\% Zn/MCM-41, B EDX of 10\% Zn/MCM-41 
Table $3 \mathrm{NH}_{3}$ and $\mathrm{CO}_{2}$ TPD of the prepared catalysts

\begin{tabular}{llll}
\hline Catalyst & $\begin{array}{l}\text { Total } \mathrm{NH}_{3} \\
\text { desorbed } \\
\left(\mathrm{mmol} \mathrm{g}^{-1}\right)\end{array}$ & $\begin{array}{l}\text { Total } \mathrm{CO}_{2} \\
\text { desorbed } \\
\left(\mathrm{mmol} \mathrm{g}^{-1}\right)\end{array}$ & $\begin{array}{l}\text { Acid/base } \\
\text { ratio }\end{array}$ \\
\hline $2 \% \mathrm{Zn} / \mathrm{MCM}-41$ & 0.3163 & 0.4192 & 0.7545 \\
$5 \% \mathrm{Zn} / \mathrm{MCM}-41$ & 0.5254 & 0.6177 & 0.8505 \\
$10 \% \mathrm{Zn} / \mathrm{MCM}-41$ & 0.5121 & 0.6201 & 0.825 \\
\hline
\end{tabular}

Table 4 Effect of different supports on activity of $\mathrm{ZnO}$ for the carbonylation of glycerol with urea

\begin{tabular}{lllllc}
\hline Sr. no. & Catalyst & Conversion (\%) & \multicolumn{3}{c}{ Selectivity $(\%)$} \\
\cline { 3 - 6 } & & & GC & GD & Other \\
\hline 1 & $5 \% \mathrm{Zn} / \mathrm{MCM}-41$ & 78 & 98 & 1 & 1 \\
2 & $5 \% \mathrm{Zn} / \mathrm{SBA}-15$ & 65 & 98 & 1 & 1 \\
4 & $5 \% \mathrm{Zn} / \mathrm{SiO}_{2}$ & 20 & 97 & 2 & 1 \\
5 & $5 \% \mathrm{Zn} / \mathrm{Al}_{2} \mathrm{O}_{3}$ & 50 & 67 & 4 & 31 \\
3 & $5 \% \mathrm{Zn} / \mathrm{ZrO}_{2}$ & 57 & 67 & 5 & 28 \\
6 & $5 \% \mathrm{Zn} / \mathrm{s}^{2} \mathrm{ZrO}_{2}$ & 54 & 97 & 2 & 1 \\
\hline
\end{tabular}

Reaction conditions: glycerol $=4.6 \mathrm{~g}$, urea $=3.08 \mathrm{~g}$, catalyst wt. $=0.23 \mathrm{~g}, 140{ }^{\circ} \mathrm{C}, 5 \mathrm{~h} ; \mathrm{N}_{2}$ flow $=20 \mathrm{~mL} / \mathrm{h}$ to remove $\mathrm{NH}_{3}$ formed during reaction

the catalyst. Among the screened catalysts, as the $\mathrm{Zn} /$ MCM-41 showed the maximum glycerol conversion and GC selectivity further studies of process optimization and catalysts stability were performed using $\mathrm{Zn} / \mathrm{MCM}-41$ catalyst and these results are discussed below.

\section{Effect of metal loading}

Effect of active metal loadings on MCM-41 support in the range of $2-10 \%$ on conversion and selectivity of GC is shown in Table 5. Surprisingly, glycerol carbonylation with urea was also observed in absence of catalyst as well as with bare MCM-41 (entries 1 and 2, Table 5). The role of $\mathrm{Zn}$ as a catalyst was evident from the enhanced glycerol conversion and GC selectivity (entries $3-5$, Table 5). The conversion of glycerol increased linearly from 63 to $82 \%$ which might be because of increase in both Lewis acid and base strength (Table 3) with increase in active metal loading from 2 to $5 \%$ while, further increase in metal loading to $10 \%$ did not affect the conversion significantly. GC selectivity observed was $92 \%$ for minimum $\mathrm{Zn}$ loading of $2 \%$ while, almost complete ( $298 \%$ ) selectivity to GC was achieved for $\mathrm{Zn}$ loading of 5 and $10 \%$ (entries 4-6, Table 5).

\section{Effect of catalyst loading}

The effect of loading of $10 \% \mathrm{Zn} / \mathrm{MCM}-41$ catalyst was also studied in the range of $0.06-0.23 \mathrm{~g}$, on activity and
Table 5 Effect of $\mathrm{Zn}$ loading on glycerol conversion and GC selectivity

\begin{tabular}{llllll}
\hline Sr. no. & Catalyst & Conversion (\%) & \multicolumn{3}{c}{ Selectivity (\%) } \\
\cline { 3 - 6 } & & & GC & GD & Other \\
\hline 1 & - & 41 & 90 & 2 & 8 \\
2 & MCM-41 & 51 & 92 & 1.7 & 6.3 \\
3 & $2 \%$ Zn/MCM-41 & 63 & 92 & 1 & 7 \\
4 & $5 \%$ Zn/MCM-41 & 82 & 98 & 1 & 1 \\
5 & $10 \%$ Zn/MCM-41 & 84 & 98 & 1 & 1 \\
\hline
\end{tabular}

Reaction conditions: glycerol $=4.6 \mathrm{~g}, \quad$ urea $=3.08 \mathrm{~g}$, catalyst wt. $=0.23 \mathrm{~g}, 140{ }^{\circ} \mathrm{C}, 5 \mathrm{~h}, \mathrm{~N}_{2}$ flow $=20 \mathrm{~mL} / \mathrm{h}$ to remove $\mathrm{NH}_{3}$ formed during reaction

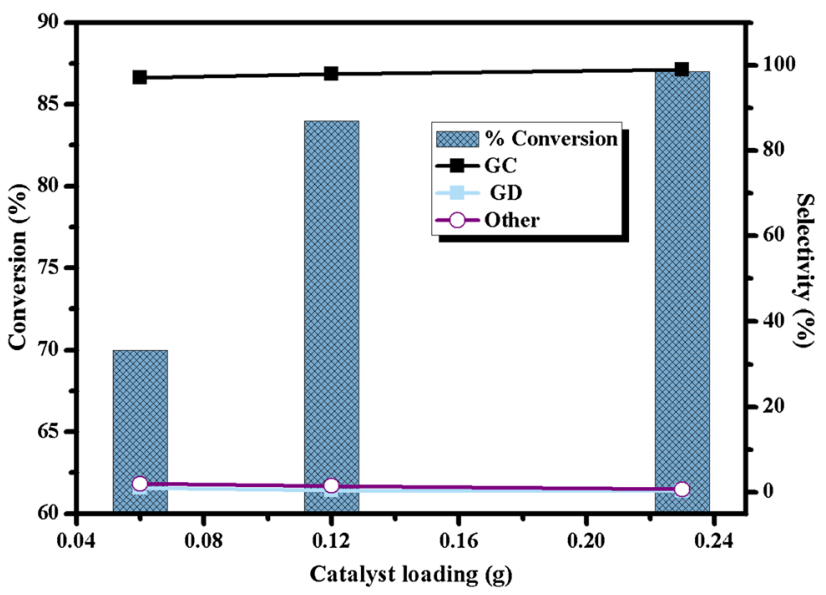

Fig. 7 Effect of catalyst loading on glycerol conversion and GC selectivity. (reaction conditions: glycerol $=4.6 \mathrm{~g}$, urea $=3.08 \mathrm{~g}$, catalyst $10 \% \mathrm{Zn} / \mathrm{MCM}-41,140{ }^{\circ} \mathrm{C}, 5 \mathrm{~h} ; \mathrm{N}_{2}$ flow $=20 \mathrm{~mL} / \mathrm{h}$ to remove $\mathrm{NH}_{3}$ formed during reaction)

GC selectivity. As seen from Fig. 7, the conversion of glycerol increased from 70 to $85 \%$ while, selectivity to GC reached almost completion (from 97 to $98 \%$ ), with about a fourfold increase in catalyst loading $(0.06-0.23 \mathrm{~g})$. This is obvious as increase in catalyst loading caused an increase in the acidic and basic sites that facilitated the carbonylation of glycerol with urea to give GC.

\section{Effect of mol ratio}

The effect of the mol ratio of glycerol to urea in the range of 1:0.5-1:2 on conversion and selectivity to GC was studied by varying the initial concentration of urea at a constant glycerol and catalyst concentration for $10 \%$ $\mathrm{Zn} / \mathrm{MCM}-41$ catalyst and the results are presented in Table 5. The conversion of glycerol was much lower (44\%) for the highest mol ratio of glycerol to urea (entry 
Table 6 Effect of glycerol: urea mole ratio on catalysts activity for carbonylation of glycerol to GC

\begin{tabular}{llllll}
\hline Sr. no. & Glycerol: Urea & Conversion (\%) & \multicolumn{3}{c}{ Selectivity (\%) } \\
\cline { 4 - 6 } & & & GC & GD & Others \\
\hline 1 & $1: 0.5$ & 44 & 98 & 1 & 1 \\
2 & $1: 1$ & 84 & 98 & 1 & 1 \\
3 & $1: 2$ & 92 & 58 & 1 & 41 \\
\hline
\end{tabular}

Reaction conditions: glycerol $=4.6 \mathrm{~g}, 10 \% \mathrm{Zn} / \mathrm{MCM}-41=0.23 \mathrm{~g}$, $140{ }^{\circ} \mathrm{C}, 5 \mathrm{~h}, \mathrm{~N}_{2}$ flow $=20 \mathrm{~mL} / \mathrm{h}$ to remove $\mathrm{NH}_{3}$ formed during reaction

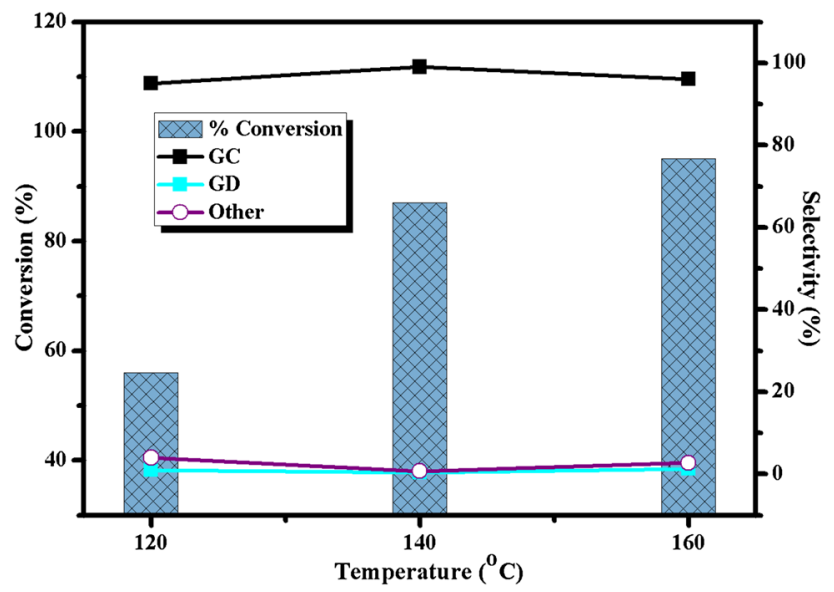

Fig. 8 Effect of temperature on glycerol conversion and GC selectivity. (reaction conditions: glycerol $=4.6 \mathrm{~g}$, urea $=3.08 \mathrm{~g}$, catalyst $10 \% \mathrm{Zn} / \mathrm{MCM}-41=0.23 \mathrm{~g}, 5 \mathrm{~h}, \mathrm{~N}_{2}$ flow $=20 \mathrm{~mL} / \mathrm{h}$ to remove $\mathrm{NH}_{3}$ formed during reaction)

1, Table 6) obviously as urea was the limiting reactant. At higher urea concentration, glycerol conversion increased up to $92 \%$ (entries 2 and 3, Table 6); however, GC selectivity dropped down considerably from 98 to $58 \%$ (entry 3, Table 6). This is because at higher urea concentration, further carbonylation of GC with urea is possible forming urethanes [38]. At 1:1 mol ratio, highest selectivity of $98 \%$ to GC was achieved with $84 \%$ conversion, suggesting that $1: 1$ was an optimum ratio of glycerol to urea to give the highest activity and selectivity to GC.

\section{Effect of the temperature}

With the glycerol to urea ratio of $1: 1$, study of effect of temperature was done by varying the temperature in a range of $120-160{ }^{\circ} \mathrm{C}$. As shown in Fig. 8, glycerol conversion linearly increased from 56 to $95 \%$ with increase in temperature from 120 to $160{ }^{\circ} \mathrm{C}$. However, at higher reaction temperature of $160{ }^{\circ} \mathrm{C}$, slight decrease in GC selectivity was observed with simultaneous increase in
Table 7 Effect of $\mathrm{N}_{2}$ flow on catalysts activity for carbonylation of glycerol to GC

\begin{tabular}{llllll}
\hline Sr. no. & $\mathrm{N}_{2}$ flow & Conversion (\%) & \multicolumn{3}{c}{ Selectivity (\%) } \\
\cline { 4 - 6 } & & & GC & GD & Others \\
\hline 1 & 10 & 60 & 86 & nd & 14 \\
2 & 20 & 84 & 98 & 1 & 1 \\
3 & 40 & 87 & 98 & 1 & 1
\end{tabular}

Reaction conditions: glycerol $=4.6 \mathrm{~g}, \quad$ urea $=3.08 \mathrm{~g}$, catalyst wt. $=0.23 \mathrm{~g}, 140{ }^{\circ} \mathrm{C}, 5 \mathrm{~h}$

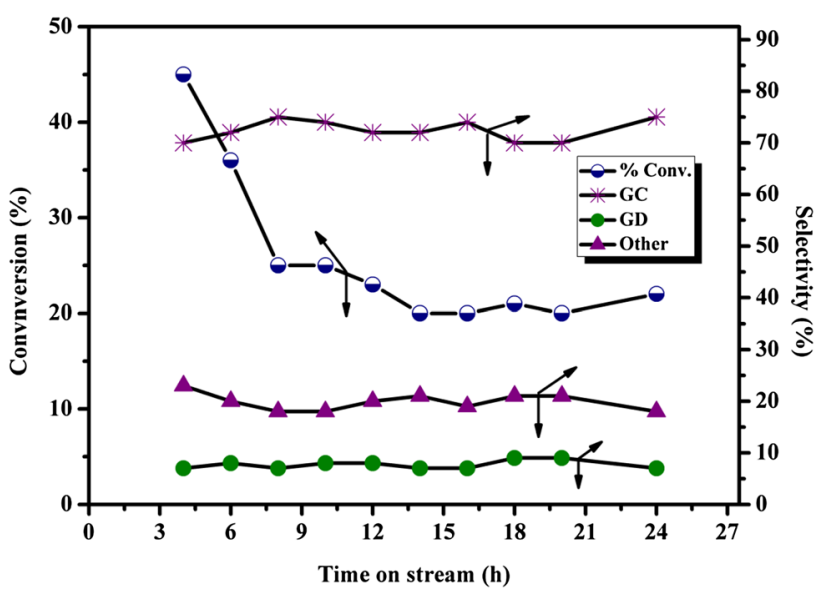

Fig. 9 Conversion and selectivity versus time profile of glycerol carbonylation in a continuous fixed bed reactor (reaction conditions: GLY-to-urea mol ratio $=1 / 1$, catalyst wt. $5 \% \mathrm{Zn} / \mathrm{MCM}-41=3 \mathrm{~g}$, $100 \mathrm{~mL}$ IPA solvent, $140{ }^{\circ} \mathrm{C}, \quad 24 \mathrm{~h}, \quad$ LHSV $=0.34 \mathrm{~h}^{-1}, \quad \mathrm{~N}_{2}$ flow $=20 \mathrm{~mL} / \mathrm{h}$ to remove $\mathrm{NH}_{3}$ formed during reaction)

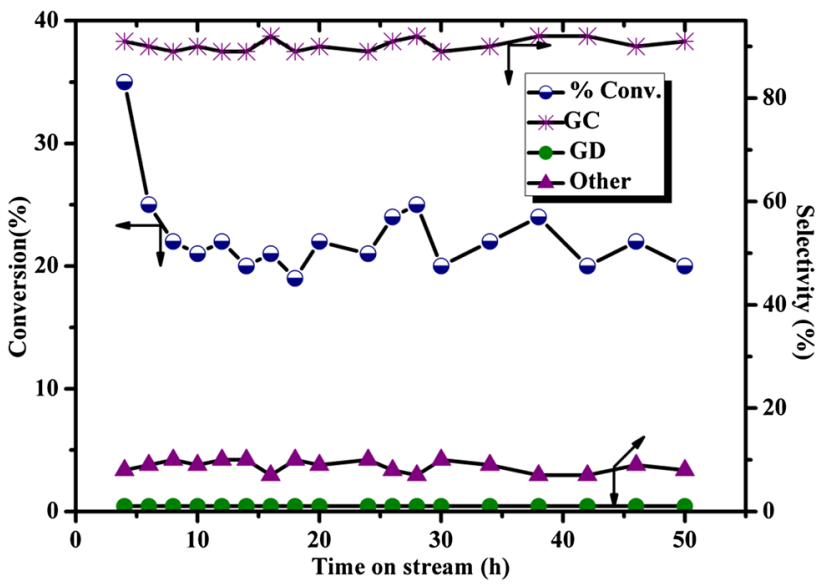

Fig. 10 Conversion and selectivity versus time profile of aqueous glycerol carbonylation in a continuous fixed bed reactor (reaction conditions: GLY-to-urea mol ratio $=1 / 1$, catalyst wt. $5 \% \mathrm{Zn} / \mathrm{MCM}-$ $41=3 \mathrm{~g}, 100 \mathrm{~mL}$ water solvent, $140{ }^{\circ} \mathrm{C}, 50 \mathrm{~h}, \mathrm{LHSV}=0.34 / \mathrm{h}, \mathrm{N}_{2}$ flow $=20 \mathrm{~mL} / \mathrm{h}$ to remove $\mathrm{NH}_{3}$ formed during reaction)

byproduct selectivity. Since, the maximum selectivity of $98 \%$ to $\mathrm{GC}$ was achieved at $140{ }^{\circ} \mathrm{C}$, it was considered as the optimum reaction temperature. 


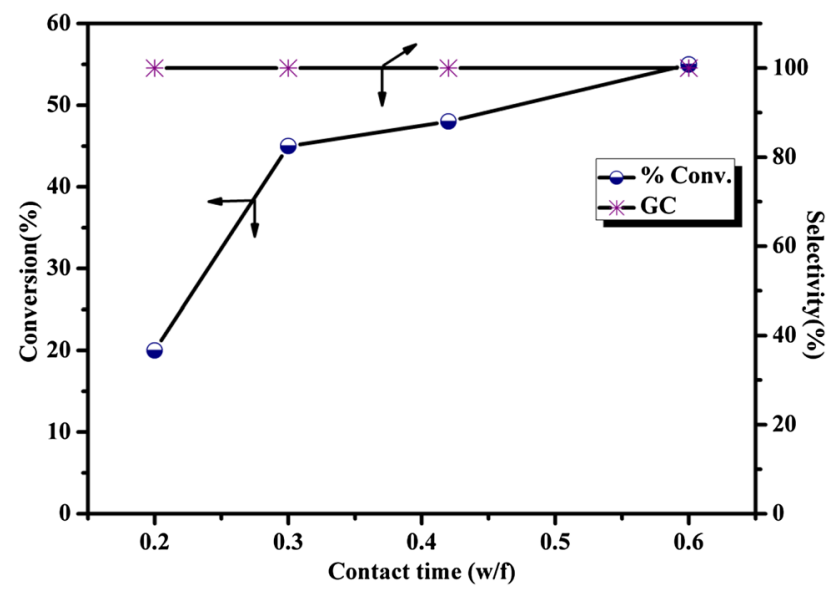

Fig. 11 Effect of contact time W/F on glycerol conversion and selectivity (reaction conditions: catalyst wt. $=3 \mathrm{~g} 200{ }^{\circ} \mathrm{C} ; 26 \mathrm{wt} \%$ aqueous glycerol)

\section{Effect of the $\mathrm{N}_{2}$ flow rate}

The effect of $\mathrm{N}_{2}$ flow rate was also studied by its variation as 10,20 and $40 \mathrm{~mL} / \mathrm{h}$ at optimum reaction temperature of $140{ }^{\circ} \mathrm{C}$ (Table 7). It was observed that both glycerol conversion and GC selectivity increased from 60 to $84 \%$ and from 86 to $98 \%$, respectively, with increase in $\mathrm{N}_{2}$ flow from 10 to $20 \mathrm{~mL} / \mathrm{h}$. However, further rise in $\mathrm{N}_{2}$ flow of $40 \mathrm{~mL} / \mathrm{h}$ showed only marginal increase in glycerol conversion of $87 \%$ while, GC selectivity remaining constant at $98 \%$. Therefore, the optimum $\mathrm{N}_{2}$ flow was considered to be $20 \mathrm{~mL} / \mathrm{h}$.

\section{Continuous operation}

From the process point of view, it was thought appropriate to study the glycerol-urea carbonylation in a continuous mode of operation. From the activity study in a batch operation, it was observed that $10 \% \mathrm{Zn}$ loading showed only marginal increase in conversion with the same selectivity to $\mathrm{GC}$ as that of $5 \% \mathrm{Zn} / \mathrm{MCM}-41$ catalyst (Table 5). Hence, further study was done with $5 \% \mathrm{Zn} /$ MCM-41 catalyst in a continuous mode of operation.

Initially, time on stream activity of $5 \% \mathrm{Zn} / \mathrm{MCM}-41$ catalyst was evaluated for continuous glycerol carbonylation in presence of 2-propanol (IPA) as a solvent. Figure 9 shows a consistent performance for $24 \mathrm{~h}$ of reaction time at $140{ }^{\circ} \mathrm{C}$ temperature and $20 \mathrm{~mL} \mathrm{~h}^{-1} \mathrm{~N}_{2}$ flow with an average glycerol conversion of $\sim 25 \%$ and GC selectivity in the range of $70-75 \%$. However, unlike the product distribution observed in the batch operation, selectivity to GC was restricted to only $75 \%$ with $\sim 10 \%$ selective formation of GD and $\sim 15 \%$ selectivity to other byproducts (Fig. 9). The possible byproducts included isopropyl carbonate and di-isopropyl carbonate obtained by transesterification of IPA with urea.

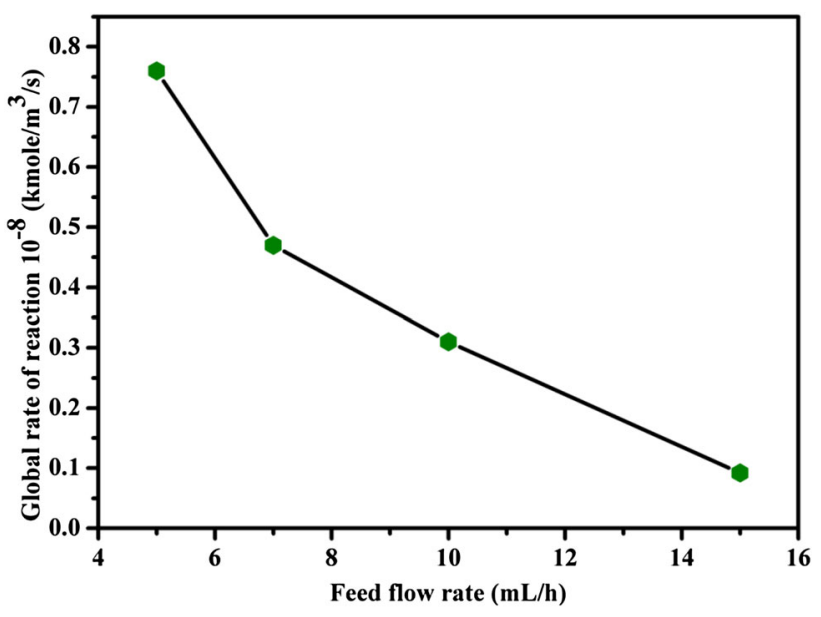

Fig. 12 Effect of liquid flow rate on global rate of glycerol carbonylation (reaction conditions: catalyst wt. $=3 \mathrm{~g}, 200^{\circ} \mathrm{C}, 26$ wt $\%$ aqueous glycerol)

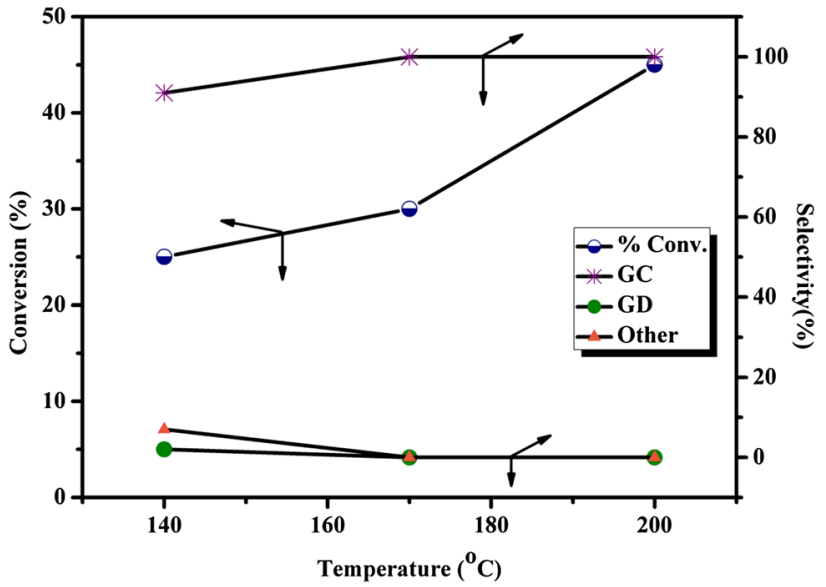

Fig. 13 Effect of temperature on glycerol conversion and product selectivity in aqueous glycerol carbonylation (reaction conditions: catalyst wt. $=3 \mathrm{~g}, 26 \mathrm{wt} \%$ aqueous glycerol, LHSV $=0.34 / \mathrm{h}$ )

Figure 10 displays the time on stream (TOS) activity of the $5 \% \mathrm{Zn} / \mathrm{MCM}-41$ catalyst in an aqueous medium for the carbonylation of glycerol to glycerol carbonate at $140{ }^{\circ} \mathrm{C}$ temperature, and $20 \mathrm{~mL} \mathrm{~h}^{-1} \mathrm{~N}_{2}$ flow. Interestingly, in contrast to IPA run, here the selectivity to GC enhanced to $\sim 91 \%$ with $\sim 9 \%$ formation of GD and other byproducts. The run started with the higher glycerol conversion of $35 \%$ which then stabilized to $25 \%$. As the change from organic solvent (IPA) to aqueous, drastically enhanced GC selectivity from 75 to $91 \%$ further studies of process optimization were done in an aqueous medium.

\section{Optimization of operating conditions}

Glycerol conversion and GC selectivity are greatly influenced by process parameters such as residence time, 


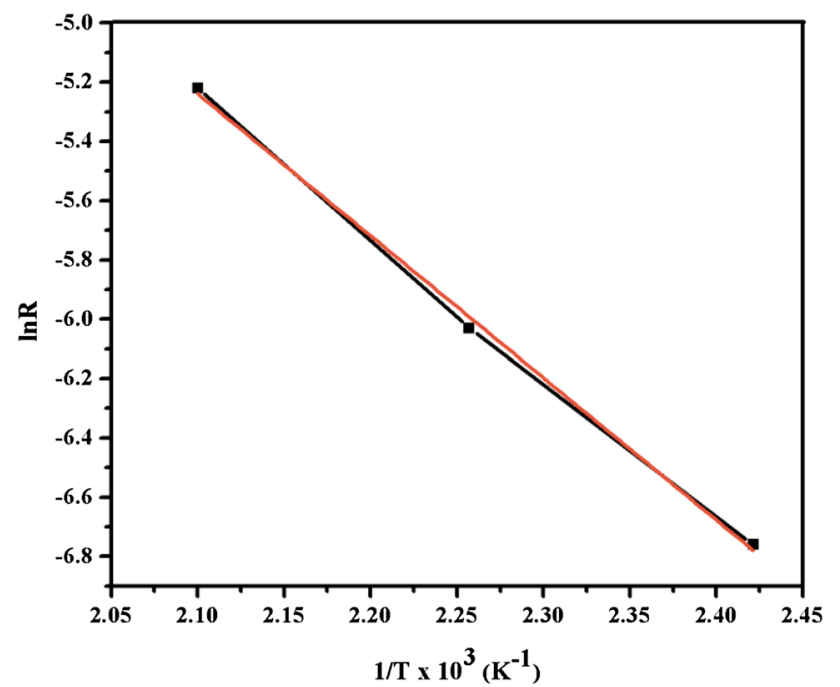

Fig. 14 Arrhenius plot (reaction conditions: catalyst wt. $=3 \mathrm{~g}, 26$ $\mathrm{wt} \%$ aqueous glycerol, LHSV $=0.34 / \mathrm{h}$ )

reaction temperature and glycerol concentration; hence, the effect of these parameters on the catalyst performance was carried out systematically and the results of which are discussed below.

The effect of liquid flow rate in terms of contact time on glycerol conversion is displayed in Fig. 11. It was observed that as the contact time increased from 0.2 to $0.3 \mathrm{~h}$, a sharp rise in the glycerol conversion from 20 to $45 \%$ was observed with almost complete selectivity to GC. Further increase in contact time from 0.3 to $0.6 \mathrm{~h}$ caused linear increase in activity in terms of conversion from 45 to $55 \%$ with complete selectivity to GC. This follows that increase in residence time directly enhanced the number of possible collisions of the reactant molecules on the surface of the catalyst for lower liquid feed rate. Thus, the highest productivity of GC was achieved at $10 \mathrm{~mL} \mathrm{~h}^{-1}$ flow rate of aqueous glycerol. The effect of liquid flow rate on the global rate of glycerol carbonylation was also studied (Fig. 12) keeping all the other parameters constant. The linear decline in global rate from $0.7 \times 10^{-8}$ to $0.09 \times 10^{-8} \mathrm{k} \mathrm{mol} \mathrm{m}^{-3} \mathrm{~s}^{-1}$ was observed with increase in liquid flow rate from $5 \mathrm{~mL}$ to $15 \mathrm{~mL} \mathrm{~h}^{-1}$. This may be due to the fact that in the lower range of liquid flow rate of $5-7 \mathrm{~mL} \mathrm{~h}^{-1}$, catalyst particles get partially wetted due to capillary action which is responsible for the direct interaction of liquid phase and solid surface of the catalyst, ultimately resulting in higher rate of carbonylation. In contrast to this, at higher liquid flow rates of $7-15 \mathrm{~mL} \mathrm{~h}^{-1}$, channelizing would hinder the access of liquid reactants to the catalyst sites resulting in the linear decrease in the global rate of carbonylation from $0.4 \times 10^{-8}$ to $0.09 \times 10^{-8} \mathrm{k} \mathrm{mol} \mathrm{m}^{-3} \mathrm{~s}^{-1}$.

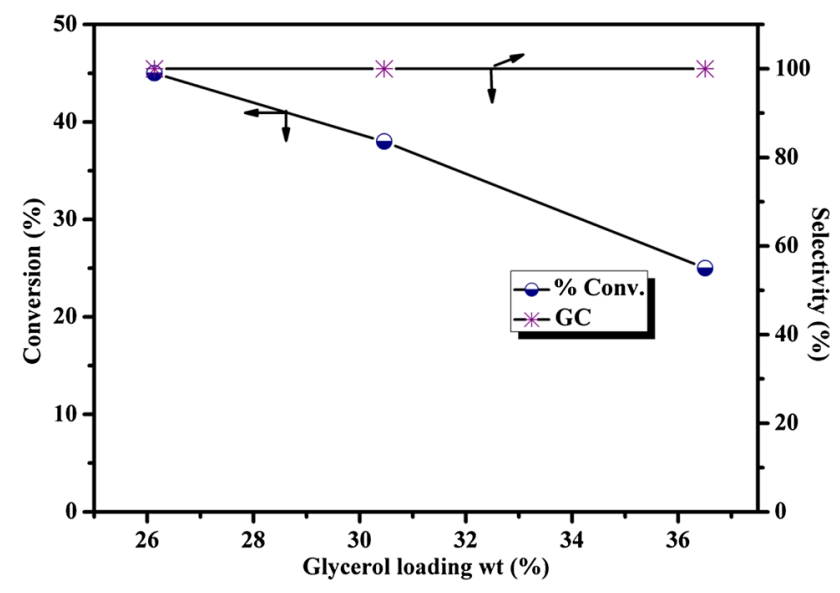

Fig. 15 Effect of glycerol loading on conversion and product selectivity in aqueous glycerol carbonylation (reaction conditions: catalyst $=3 \mathrm{~g}, 200^{\circ} \mathrm{C} ; \mathrm{LHSV}=0.34 / \mathrm{h}$ )

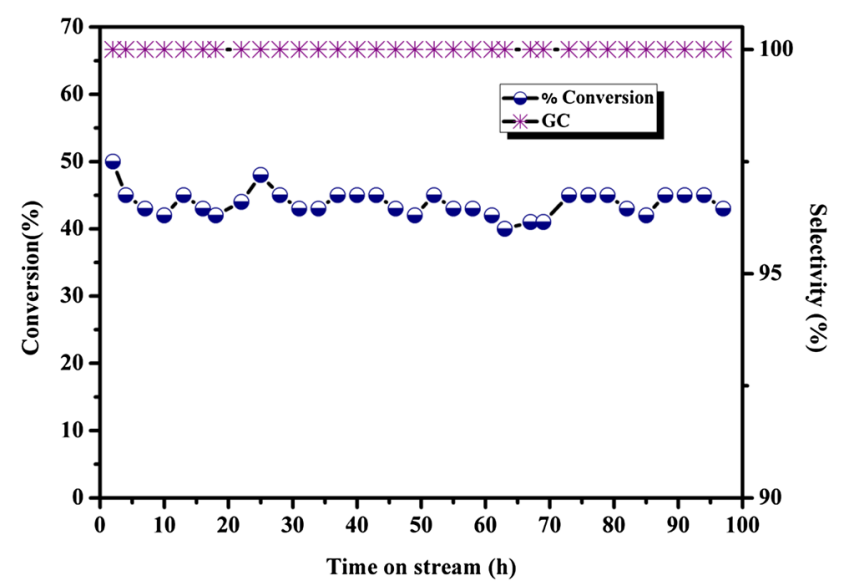

Fig. 16 Conversion versus time profile of aqueous glycerol carbonylation (reaction conditions: GLY-to-urea mol ratio $=1 / 1$, catalyst wt. $=3 \mathrm{~g} 100 \mathrm{~mL}$ water solvent, $200{ }^{\circ} \mathrm{C} ; \mathrm{LHSV}=0.34 / \mathrm{h}$ )

Figure 13 exhibits the effect of temperature on the glycerol conversion and GC selectivity in the carbonylation of glycerol with urea. With increase in temperature from 140 to $200{ }^{\circ} \mathrm{C}$, a gradual increase in the glycerol conversion was observed along with simultaneous increase in GC selectivity from 91 to $100 \%$. The rise in temperature from 140 to $170{ }^{\circ} \mathrm{C}$ resulted in marginal increase in glycerol conversion from 25 to $30 \%$. However, further increase in temperature up to $200{ }^{\circ} \mathrm{C}$, resulted in considerable increase in glycerol conversion from 30 to $45 \%$ with complete selectivity to GC without formation of any byproduct. Therefore, the optimum reaction temperature for the glycerol carbonylation was found to be $200{ }^{\circ} \mathrm{C}$. Activation energy estimated from the Arrhenius plot was found to be $39.82 \mathrm{~kJ} \mathrm{~mol}^{-1}$, suggesting glycerol carbonylation reaction was kinetically controlled, under the present set of reaction conditions (Fig. 14). 

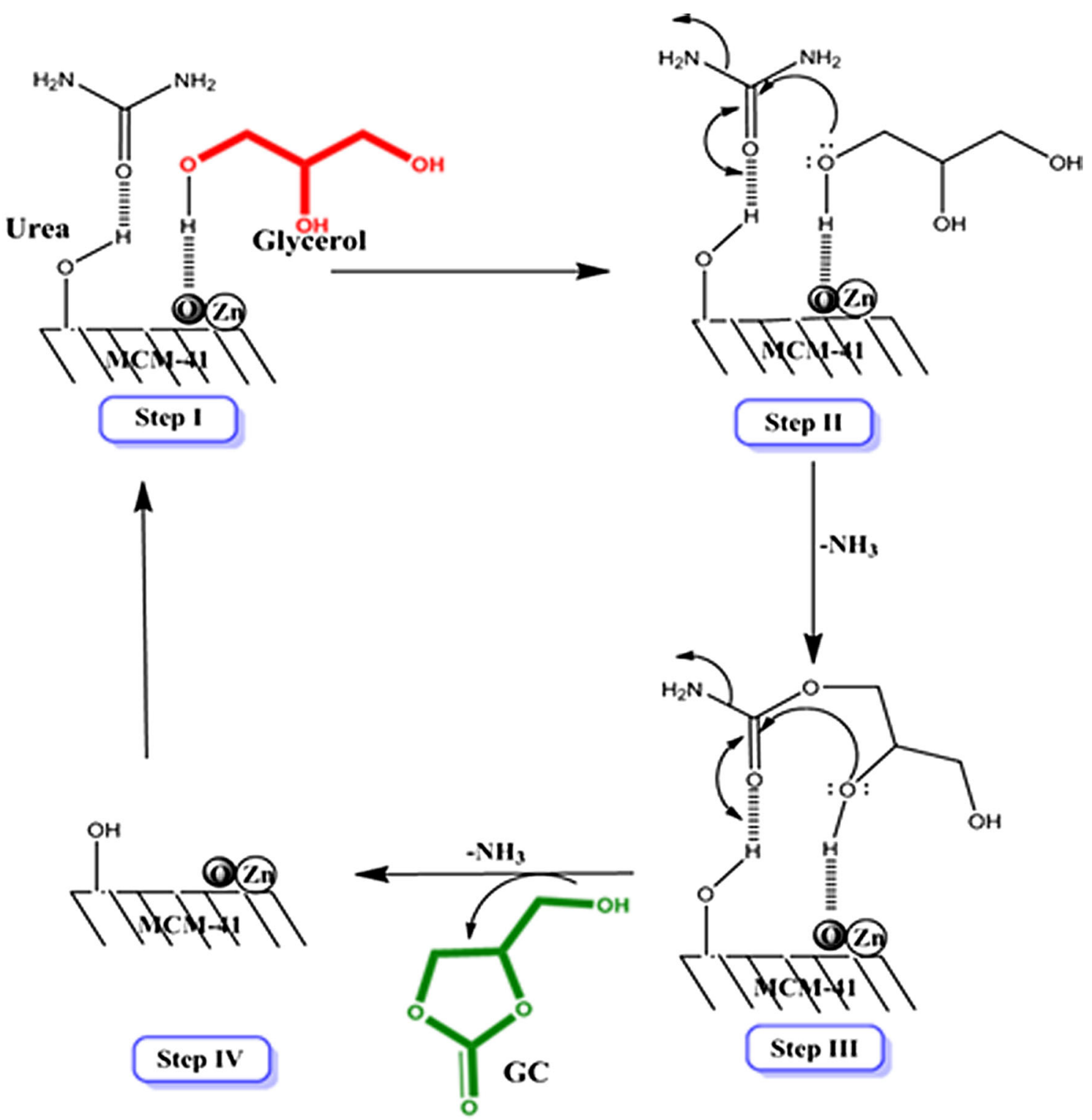

Step III

Scheme 2 Proposed mechanism for carbonylation of glycerol with urea to GC

Effect of glycerol loading on the catalytic activity for the glycerol carbonylation is shown in Fig. 15. Increase in glycerol loading from 26 to $36 \%$ caused twofold decrease in glycerol conversion was observed, without affecting the GC selectivity of $100 \%$. This indicates that increased glycerol loading resulted in increased viscosity of the solution due to which substrate get strongly adsorbed on the active sites of the catalyst leading to the deactivation of catalytic activity.

Figure 16 shows the time on stream activity of $5 \% \mathrm{Zn} /$ MCM-41 catalyst of $100 \mathrm{~h}$ at $200{ }^{\circ} \mathrm{C}, 10 \mathrm{~mL} \mathrm{~h}^{-1}$ feed flow and $20 \mathrm{~mL} \mathrm{~h}^{-1} \mathrm{~N}_{2}$ flow. Glycerol conversion was $50 \%$ within first $2 \mathrm{~h}$ after which it decreased slightly to $45 \%$ and then remained constant up to $\sim 97 \mathrm{~h}$ of reaction time whereas, the GC selectivity was not affected (100\%). As we compared the GC productivity in batch and continuous operation, the GC productivity in batch was five times $\left(6.9 \mathrm{~h}^{-1}\right)$ higher than that of continuous operation $\left(1.38 \mathrm{~h}^{-1}\right)$. This was due to higher residence time in a batch operation.

To confirm the glycerol conversion determined by gas chromatography of liquid samples, the quantification of $\mathrm{NH}_{3}$ released during the reaction was also carried out for few experiments. For this purpose, $\mathrm{NH}_{3}$ evolved from the reaction was dissolved in water at the reactor outlet using $\mathrm{N}_{2}$ as a carrier gas. The total amount of ammonia released was analyzed by volumetric analysis of both the reactor outlet gas sample and liquid reaction crude against strong 
$0.5 \mathrm{M} \mathrm{HCl}$. The total amount of $\mathrm{NH}_{3}$ released was found to be $2.71 \mathrm{~g}$ which was in good agreement with the theoretically obtained value for $45 \%$ of glycerol conversion.

\section{A possible reaction mechanism for carbonylation of glycerol with urea over $\mathrm{Zn} / \mathrm{MCM}-41$ catalyst}

It is important to note that the present reaction of glycerol with urea to form GC proceeds without a catalyst under standard reaction conditions but with only $40 \%$ conversion and $90 \%$ selectivity to glycerol carbonate (entry 1, Table 5). In presence of Zn-based catalyst, glycerol conversion enhanced by twofold (87\%) with almost complete selectivity towards GC. It was also observed that the parent MCM-41 showed 51\% conversion of glycerol, as the $\mathrm{OH}$ groups of surface silanol can activate the urea molecule as shown in Scheme 2 (step I) [40]. In step II, Lewis basic sites of $\mathrm{ZnO}$ can activate glycerol molecule, which is then prone to the attack on carbonyl carbon of urea with simultaneous release of $1 \mathrm{~mol}$ of $\mathrm{NH}_{3}$. In the next step (III) secondary $-\mathrm{OH}$ of activated glycerol again attacks over carbonyl carbon of urea to form five membered cyclic glycerol carbonate with the loss of second molecule of $\mathrm{NH}_{3}$. In the last step IV of the reaction pathway, the catalyst surface was regenerated by the release of GC. This suggests that the $\mathrm{ZnO}$ and MCM-41 play cooperative role in glycerol carbonylation reaction. This was confirmed by control experiment with only bare $\mathrm{ZnO}$ which gave lower glycerol conversion of $68 \%$ compared to that of $5 \% \mathrm{Zn} /$ MCM-41 (78\%) with GC selectivity of $98 \%$ (entry 3, Table 5).

\section{Conclusion}

Among the several acidic supports (MCM-41, SBA-15, $\mathrm{SiO}_{2}, \mathrm{Al}_{2} \mathrm{O}_{3}, \mathrm{ZrO}_{2}$ and s- $\mathrm{ZrO}_{2}$ ) studied for $\mathrm{ZnO}$ catalyst for the glycerol-urea carbonylation, MCM-41 supported $\mathrm{Zn}$ catalyst exhibited the highest activity and almost complete selectivity to GC. Increased $\mathrm{Zn}$ loading in the rang of $2-10 \%$ on MCM-41, resulted in decrease in surface area from 692 to $498 \mathrm{~m}^{2} \mathrm{~g}^{-1}$ confirming well dispersed $\mathrm{ZnO}$ within the mesoporous structure of silicalite MCM41 which also affect the ordering of the mesoporous structure evident from the XRD analysis. The increased dispersion of $\mathrm{Zn}$ with increase in loading has directly reflected in the enhancement of GC yield from 57 to $83 \%$. Interestingly, acidity/basicity ratio was found to be constant ( $\sim 0.8$ ) for $\mathrm{Zn}$ loading in the range of $2-10 \%$ while, the glycerol conversion increased substantially with increase in $\mathrm{Zn}$ loading irrespective of the acid/base ratio. Glycerol conversion increased linearly from 63 to $82 \%$ with increase in active metal loading from 2 to $5 \%$ due to higher availability of Lewis acid-base sites generated from $\mathrm{ZnO}$. While, the GC selectivity marginally increased from 92 to almost complete $(98 \%)$ for $>2 \% \mathrm{Zn}$ loading. Glycerol conversion and GC selectivity were found to be quite sensitive to glycerol to urea mole ratios. For higher mole ratio (2) of glycerol to urea, glycerol conversion dropped down to $44 \%$ while, for lower ratio of 0.5 , GC selectivity was only $58 \%$ with the formation of urethanes as the byproducts. In a proposed reaction pathway, $\mathrm{OH}$ groups of silanol are shown to activate the urea molecule while Lewis basic sites of $\mathrm{ZnO}$ can activate glycerol molecule, which is then prone to attack on carbonyl carbon of urea followed by cyclisation and generating two molecules of $\mathrm{NH}_{3}$.

In a batch operation, glycerol conversion as high as $78 \%$ with almost complete selectivity to GC could be achieved at $140{ }^{\circ} \mathrm{C}$; however, a lower glycerol conversion of $55 \%$ was achieved even at higher temperature of $200{ }^{\circ} \mathrm{C}$, in a continuous operation over the same catalyst. This was because of $\sim 5$ times lower residence time in a continuous operation than that in a batch operation. The activation energy calculated from Arrhenius plot was found to be $39.82 \mathrm{~kJ} \mathrm{~mol}^{-1} \mathrm{~K}^{-1}$. Hence, the batch operation could be better, giving fivefold higher productivity of GC as compared to the continuous for carbonylation of glycerol with urea.

Acknowledgements One of the authors SEK is thankful to the Council of Scientific and Industrial Research, New Delhi, for its financial support for the award of Senior Research Fellowship.

Open Access This article is distributed under the terms of the Creative Commons Attribution 4.0 International License (http:// creativecommons.org/licenses/by/4.0/), which permits unrestricted use, distribution, and reproduction in any medium, provided you give appropriate credit to the original author(s) and the source, provide a link to the Creative Commons license, and indicate if changes were made.

\section{References}

1. BP Statistical Review of World Energy June (2012). http://www. bp.com/statisticalreview

2. Zhou CH, Beltramini JN, Fan YX, Lu GQ (2008) Chemoselective catalytic conversion of glycerol as a biorenewable source to valuable commodity chemicals. Chem Soc Rev 37:527-549

3. Meessen JH, Petersen H (2000) Ammonia and Fertilizers. WileyVCH Verlag GmbH \& Co. KGaA, Wrocław, Poland

4. Sakakura T, Choi JC, Yasuda H (2007) Transformation of carbon dioxide. Chem Rev 107:2365-2387

5. Du Y, Cai F, Kong DL, He LN (2005) Organic solvent-free process for the synthesis of propylene carbonate from supercritical carbon dioxide and propylene oxide catalyzed by insoluble ion exchange resins. Green Chem 7:518-523

6. Doro F, Winnertz P, Leitner W, Prokofieva A, Muller TE (2011) Adapting a Wacker-type catalyst system to the palladium-catalyzed oxidative carbonylation of aliphatic polyols. Green Chem $13: 292-295$ 
7. Teles JH, Rieber N, Harder W (1994) Preparation of glyceryl carbonate. US patent 5359094

8. Li J, Gu Y, Guan Z, Mo W, Ni Y, Li T, Li G (2010) Oxidative carbonylation of glycerol to glycerol carbonate by $\mathrm{PdCl}_{2}$ (Phen)/ KI. Appl Catal A 386:188-193

9. Casiello M, Monopol A, Cotugno P, Milella A, Michela M, Ciminale F, Nacci A (2014) Copper(II) chloride-catalyzed oxidative carbonylation of glycerol to glycerol carbonate. J Mol Catal A Chem 381:99-106

10. Hu J, Gu Y, Guan Z, Li J, Mo W, Li T, Li G (2011) An efficient palladium catalyst system for the oxidative carbonylation of glycerol to glycerol carbonate. Chemsuschem 4:1767-1772

11. Appaturi JN, Ng EP, Adam F (2014) Solid imidazolium amide catalysts for the solvent free synthesis of glycerol carbonate. J CO2 Util 6:69-74

12. Alvarez MG, Pliskova M, Segarra AM, Medina F, Figureas F (2012) Synthesis of glycerol carbonates by transesterification of glycerol in continuous system using supported hydrotalcites as catalyst. Appl Catal B 113-114:212-220

13. Aresta M, Dibenedetto A, Nocito F, Ferragina C (2009) Valorization of bio-glycerol: New catalytic materials for the synthesis of glycerol carbonate via glycerolysis of urea. J Catal 268:106-114

14. Vieville C, Yoo JW, Pelet S, Mouloungui Z (1998) Synthesis of glycerol carbonate by direct carbonatation of glycerol in supercritical $\mathrm{CO}_{2}$ in the presence of zeolites and ion exchange resins. Catal Lett 56:245-247

15. Fukuda Y, Yamamoto Y (2009) Method for producing glycerol derivative. JP Patent 023930

16. Kondawar SE, Rode CV (2017) Tandem synthesis of glycidol via transesterification of glycerol with DMC over Ba-mixed metal oxide catalysts. ACS Sustain Chem Eng 5:1763-1774

17. Ochoa-Gomez JR, Gomez-Jimenez-Aberasturi O, MaestroMadurga B, Pesquera- Rodriguez A, Ramirez-Lopez C, LorenzoIbarreta L, Torrecilla-Soria J, Villaran-Velasco MC (2009) Synthesis of glycerol carbonate from glycerol and dimethyl carbonate by transesterification: catalyst screening and reaction optimization. Appl Catal A 366:315-324

18. Mouloungui Z, Yoo JW, Gachen CA, Gaset A, Vermeersch G (1996) Process for the preparation of glycerol carbonat from glycerol and a cyclic organic carbonat, especially ethylene or propylene carbonate. E P Patent 96-390003 739888

19. Li J, Wang T (2011) On the deactivation of alkali solid catalysts for the synthesis of glycerol carbonate from glycerol and dimethyl carbonate. React Kinet Mech Catal 102:113-117

20. Okutsu M, Kitsuki T (2000) Process for the preparation of glycerol carbonate. WO Patent JP 050415

21. Kumar P, With P, Srivastava VC, Glaser R, Mishra IM (2015) Glycerol carbonate synthesis by hierarchically structured catalysts: catalytic activity and characterization. Ind Eng Chem Res 54:12543-12552

22. Sasa T, Okutsu T, Uno M (2008) Method for producing glycerol carbonate. JP Patent 285457

23. Sasa T, Okutsu T, Uno M (2009) Method for producing glycerol carbonate. JP Patent 067689

24. Yoo JW, Mouloungui Z (2003) Catalytic carbonylation of glycerin by urea in the presence of zinc mesoporous system for the synthesis of glycerol carbonate. Stud in Surf Sci Catal 146:757-760
25. Climent MJ, Corma A, De Frutos P, Iborra S, Noy M, Veltyand A, Concepcion P (2010) Chemicals from biomass: Synthesis of glycerol carbonate by transesterification and carbonylation with urea with hydrotalcite catalysts. The role of acid-base pairs. J Catal 269:140-149

26. Rubio-Marcos F, Calvino-Casilda V, Banares MA, Fernandez JF (2010) Novel hierarchical $\mathrm{Co}_{3} \mathrm{O}_{4} / \mathrm{ZnO}$ mixtures by dry nanodispersion and their catalytic application in the carbonylation of glycerol. J Catal 275:288-293

27. Wang L, Ma Y, Wang Y, Liu S, Deng Y (2011) Efficient synthesis of glycerol carbonate from glycerol and urea with lanthanum oxide as a solid base catalyst. Catal Commun 12:1458-1462

28. Hammond C, Lopez-Sanchez J, Rahim M, Dimitratos N, Jenkins R, Carley A, He Q, Kiely C, Knight D, Hutchings G (2011) Synthesis of glycerol carbonate from glycerol and urea with goldbased catalysts. Dalton Trans 40:3927-3937

29. Srikanth A, Viswanadham B, Kumar VP, Anipindi NR, Chary VRK (2016) Synthesis and characterization of Cs-exchanged heteropolyacid catalysts functionalized with $\mathrm{Sn}$ for carbonolysis of glycerol to glycerol carbonate. Appl Petrochem Res 6:145-153

30. Kondawar SE, Potdar AS, Rode CV (2015) Solvent-free carbonylation of glycerol with urea using metal loaded MCM-41 catalysts. RSC Adv 5:16452-16460

31. Zhao D, Feng J, Huo Q, Molish N, Fredrickson GH, Chmelka BF, Stucky GD (1998) Triblock copolymer syntheses of mesoporous silica with periodic 50 to 300 angstrom pores. Science 279:548-552

32. Alarcon EA, Villa AL, de Correa CM (2009) Characterization of Sn- and Zn-loaded MCM-41 catalysts for nopol synthesis. Micro Meso Mater 122:208-215

33. Jiang Q, Wu ZY, Wang YM, Cao Y, Zhou CF, Zhu JH (2006) Fabrication of photoluminescent $\mathrm{ZnO} / \mathrm{SBA}-15$ through directly dispersing zinc nitrate into the as-prepared mesoporous silica occluded with template. J Mater Chem 16:1536-1542

34. Zhong S, Liang L, Liu M, Liu B, Sun J (2015) DMF and mesoporous $\mathrm{Zn} / \mathrm{SBA}-15$ as synergistic catalysts for the cycloaddition of $\mathrm{CO}_{2}$ to propylene oxide. J CO2 Util 9:58-65

35. Sauer J, Marlow F, Schuth F (2001) Simulation of powder diffraction patterns of modified ordered mesoporous materials. Phys Chem Chem Phy 3:5579-5584

36. Hazrati N, Abdouss M, Vahid A, Miran Beigi AA, Mohammadalizadeh A (2014) Removal of $\mathrm{H}_{2} \mathrm{~S}$ from crude oil via stripping followed by adsorption using $\mathrm{ZnO} / \mathrm{MCM}-41$ and optimization of parameters. Int J Environ Sci Technol 11:997-1006

37. Turco M, Bagnasco G, Cammarano C, Senese P, Costantino U, Sisani M (2007) $\mathrm{Cu} / \mathrm{ZnO} / \mathrm{Al}_{2} \mathrm{O}_{3}$ catalysts for oxidative steam reforming of methanol: the role of $\mathrm{Cu}$ and the dispersing oxide matrix. Appl Catal B Envi 77:46-57

38. Silvestre-Albero J, Sepulveda-Escribano A, Rodrıguez Reinoso F (2008) Preparation and characterization of zinc containing MCM41 spheres. Micro Meso Mater 113:362-369

39. Turney TW, Patti A, Gates W, Shaheen U, Kulasegaram S (2013) Formation of glycerol carbonate from glycerol and urea catalysed by metal monoglycerolates. Green Chem 15:1925-1931

40. Zhang X, Zhao N, Wei W, Sun Y (2006) Chemical fixation of carbon dioxide to propylene carbonate over amine-functionalized silica catalysts. Catal Today 115:102-106 